\title{
DISEÑO DE UN COMPONENTE TIBIAL PERSONALIZADO CON SISTEMA DE FIJACIÓN PRESS-FIT PARA UN SISTEMA DE REEMPLAZO DE RODILLA PARA SU FABRICACIÓN MEDIANTE DMLS
}

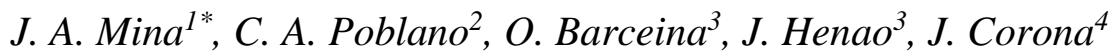

1: Investigador, CIATEQ A.C., Av. Manantiales 23-A, Parque Industrial Bernardo Quintana, El Marqués, Querétaro, 76246, México.

2: Investigador, CIATEQ A.C., Av. Manantiales 23-A, Parque Industrial Bernardo Quintana, El Marqués, Querétaro, 76246, México.

3: Investigador, Centro de Investigación en Ciencia Aplicada y Tecnología Avanzada del Instituto Politécnico Nacional IPN, CICATA Unidad Querétaro, Cerro Blanco N 141, Col. Colinas del Cimatario, 76090, México. 4: Catedrático, CONACyT-CIATEQ A.C., Av. Manantiales 23-A, Parque Industrial Bernardo Quintana, El Marqués, Querétaro, 76246, México.

* jhoan.mina@ciateq.edu.mx

\begin{tabular}{ll}
\hline PALABRAS CLAVE & RESUMEN \\
\hline Manufactura aditiva & Los diseños de sistemas de reemplazo ortopédico personalizados representan un \\
Prótesis de rodilla & nuevo desafío para la industria biomédica actual; las características anatómicas del \\
Estructura giroide & paciente y la densidad del tejido óseo que reemplazan son los dos elementos \\
Personalización & primordiales para el diseño de dichos dispositivos. El presente proyecto describe \\
Diseño & un protocolo para el diseño de un platillo tibial para un sistema de reemplazo total \\
& de rodilla basado en la información obtenida a partir de tomografía computacional \\
& de rayos X; dentro del protocolo se describe el cálculo de la densidad ósea aparente \\
& a partir de dicha información, así como la determinación de algunas constantes \\
& mecánicas como el módulo de Young y el coeficiente de Poisson, entre otras. \\
& Finalmente, los resultados de la densidad ósea aparente fueron comparados con \\
& valores de densidad obtenida en estructuras celulares tipo giroide, previamente \\
& desarrolladas por el grupo de trabajo. De igual forma, se presenta el diseño de un \\
& vástago de fijación tipo press-fit empleando este tipo de estructura celular. \\
\hline
\end{tabular}


J. A. Mina, C. A. Poblano, O. Barceinas, J. Henao, J. Corona

Revista Colombiana de Materiales, ISSN 2256-1013, No 17, pp. 53-71, 2021. http://doi.org/10.17533/udea.rcm.n17a06

\section{DESIGN OF A CUSTOMIZED PRESS-FIT TIBIAL COMPONENT FOR A KNEE REPLACEMENT SYSTEM FOR ITS MANUFACTURE THROUGH DMLS}

\begin{tabular}{ll}
\hline KEYWORDS & ABSTRACT \\
\hline $\begin{array}{l}\text { Additive manufacturing } \\
\text { Gyroid structure }\end{array}$ & $\begin{array}{l}\text { Custom orthopedic replacement system designs represent a new challenge for } \\
\text { biomedical industry; the anatomical characteristics of the patient and the density } \\
\text { of the bone tissue to be replaced are two essential elements for the design and } \\
\text { manufacture of such devices. The present project describes a protocol for the } \\
\text { development of a tibial plateau design for a total knee replacement system based } \\
\text { on the information obtained from X-ray computational tomography. The protocol } \\
\text { describes the measurement of the apparent bone density based on this } \\
\text { information; also, the determination of some mechanical constants such as } \\
\text { Young's modulus and Poisson's ratio. Finally, the results of the apparent bone } \\
\text { density were compared with values of density obtained in gyroid cell structures, } \\
\text { previously developed by the work group. Likewise, the design of a press-fit } \\
\text { fixation stem using this type of cellular structure is presented. }\end{array}$ \\
\hline
\end{tabular}

\section{INTRODUCCIÓN}

Las técnicas de manufactura aditiva han representado una nueva oportunidad para la fabricación de piezas de diferentes tamaños y de geometrías de alta complejidad. En concordancia con las necesidades crecientes de la industria biomédica, se han realizado diferentes investigaciones relacionadas con el desarrollo de sistemas de reemplazo y dispositivos implantables. Es importante reconocer que México en la actualidad cuenta con una clasificación baja $(5$, según LENS.ORG) en relación con la producción investigativa en el diseño/fabricación de sistemas de reemplazo de rodilla, razón por la que se vuelve imperativa la realización de investigaciones como la presente en el país [1]. En México, a partir de 2005 se han registrado diferentes solicitudes de patente en sistemas de reemplazo de rodilla completos, diseños de componente patelar y femoral, así como también en sistemas de reemplazo de naturaleza robótica [1], [2] y [3], de lo cual es importante resaltar que el desarrollo de prótesis obtenidas por manufactura aditiva representa un alto potencial como temática de investigación.

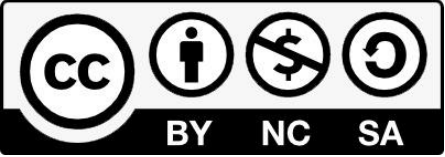

Por otra parte, diferentes autores han mencionado que los sistemas de reemplazo ortopédico, especialmente los sometidos a cargas cíclicas de compresión, tienden a presentar problemas de blindaje de esfuerzos, el cual se define como la desmineralización del hueso a causa de la reducción de las tensiones mecánicas experimentadas por el tejido óseo. Este fenómeno generalmente sucede al implantar un material con propiedades mecánicas superiores a las del hueso humano promoviendo la reducción de la densidad ósea, la disminución en la resistencia mecánica del hueso, y el aflojamiento aséptico. [4]. El aflojamiento protésico, en implantes de rodilla, es responsable de producir fatiga mecánica por desajuste, así como de incrementar el desgaste abrasivo y adhesivo de algunos componentes del implante [5].

Existen diferentes padecimientos del sistema esquelético que hacen obligatoria la intervención quirúrgica para un reemplazo parcial o total de rodilla; la osteoartritis, consiste en el desgaste progresivo y anormal del cartílago, lo cual causa dolor y rigidez en la rodilla debido a que el cartílago representa una capa firme y elástica que facilita el 
J. A. Mina, C. A. Poblano, O. Barceinas, J. Henao, J. Corona

Revista Colombiana de Materiales, ISSN 2256-1013, No 17, pp. 53-71, 2021. http://doi.org/10.17533/udea.rcm.n17a06

movimiento de los cóndilos femorales sobre el platillo tibial [6]. El exceso de peso, una lesión en la articulación, debilidad muscular, daños en los nervios e incluso factores hereditarios pueden ocasionar problemas de desgaste excesivo y pueden obligar a la realización de una artroplastia [7].

Desde el punto de vista de la biomecánica, el movimiento anatómico es vital para prevenir el aflojamiento de la prótesis, esto sugiere que es posible prevenir la perdida de la fijación, las sobrecargas y los aflojamientos cuando los movimientos no son restringidos por esfuerzos tipo cortante o rotacionales y son conducidos por el tejido blando y no por los componentes protésicos [8]. La calidad del hueso constituye uno de los factores más importantes en el éxito de la fijación de una prótesis; cuando se está ejecutando una artroplastia, se remueve el hueso subcondral, lo que deja un hueso mucho más suave para la fijación de los componentes, el hueso esponjoso de la tibia proximal [9]. Se esperaría que las fuerzas siguieran el camino más corto hacia la estructura más resistente; sin embargo, esto depende de la longitud del vástago intramedular, si el vástago es muy largo, puede ocasionar que los esfuerzos sean transmitidos directamente a la corteza distal sin pasar por la tibia proximal, lo que puede causar un atrofiamiento del hueso y posteriormente una resección ósea o un blindaje de esfuerzos que lleve al aflojamiento y falla de la pieza implantada [10].

Es importante remarcar la importancia del diseño del vástago del componente tibial en prótesis de rodilla, ya que tiene una relación directa con la posibilidad del efecto del blindaje de esfuerzos, así como la deformación y la transferencia de carga en el hueso. El conocimiento de la anatomía ósea es primordial para el diseño de una pieza implantable; la metáfisis tibial corresponde al coloquialmente conocido cuello del hueso tibial; cada hueso largo del esqueleto humano está compuesto por dos metáfisis, esta zona de la tibia se caracteriza por estar compuesta en su exterior por hueso cortical y en el interior por hueso esponjoso [11]. Durante el procedimiento de colocación de un implante esta zona es perforada, ya que en ella se ubica el vástago del componente tibial, de forma tal que los esfuerzos mecánicos se centran en esta zona donde por efecto de la perforación, la resistencia se ve ampliamente afectada en función del tamaño del vástago [12].

La trasferencia de esfuerzos del vástago central al hueso depende en gran medida de la longitud y rigidez de la pieza, así también como de la rigidez del hueso receptor [13]. Algunos estudios sugieren que el uso de vástagos no cementados puede reducir hasta en un 60\% la deformación en la zona proximal de la tibia, dependiendo de la densidad ósea y del material empleado para la fabricación de la pieza [14]. El sistema de fijación press-fit consiste en un sistema de ajuste de prótesis sin la aplicación de una capa o material intermedio que, en principio, promueva el crecimiento del hueso en la metáfisis por efecto del contacto del vástago con la zona endosteal, en donde se aplicarán los esfuerzos; eliminando así la necesidad del uso de un cemento [15].

Partiendo del precepto que el desarrollo de prótesis con morfología anatómica basada en la morfología ósea del paciente podría permitir un mejor desempeño mecánico que una prótesis de uso comercial, y que el uso de un vástago de sujeción en el componente tibial de naturaleza press-fit con estructura celular permite una mejor distribución de cargas en la tibia, se propone la construcción de un protocolo de fabricación de un componente tibial para el sistema de reemplazo total de rodilla, el cual, a partir de imágenes de tomografía computarizadas de 
J. A. Mina, C. A. Poblano, O. Barceinas, J. Henao, J. Corona

Revista Colombiana de Materiales, ISSN 2256-1013, No 17, pp. 53-71, 2021. http://doi.org/10.17533/udea.rcm.n17a06

rayos $\mathrm{X}$, sea personalizado y adaptado a las condiciones óseas de un paciente.

Con el uso de la manufactura aditiva ha sido posible diseñar y fabricar prótesis hechas a la medida para cada paciente que se puedan adaptar a las geometrías anatómicas únicas de cada paciente [16]; por otra parte, por medio de las facilidades que ofrecen las técnicas de manufactura aditiva ha sido posible integrar estructuras porosas como alternativa al uso de cementos acrílicos para la fijación protésica [17].

La identificación de las características óseas en datos tomográficos se basa principalmente en la interpretación de las imágenes en blanco, negro y escala de grises que se producen a través de la variación en los valores del coeficiente de atenuación lineal, lo cual puede entenderse como la habilidad de un material para detener fotones. Esta propiedad depende fundamentalmente del número atómico, la densidad del material y de dos mecanismos básicos de interacción: el efecto Compton y el efecto fotoeléctrico [18]. El coeficiente de atenuación lineal está directamente relacionado con el color blanco, a mayor coeficiente de atenuación, más blanco se visualizará el material en la imagen; de forma intuitiva se espera que los materiales de menor atenuación lineal dejen pasar mayor cantidad de rayos $X$ y por eso se ven más oscuros en la imagen [19].

Los archivos médicos provenientes de las tomografías computacionales representan una gran fuente de información, estudios realizados a nivel mundial muestran diferentes métodos para la determinación de la densidad ósea aparente. Por otra parte, ha sido posible comprender las características morfológicas de los huesos, los diferentes padecimientos en las articulaciones, así como la reconstrucción de fragmentos óseos e incluso piezas completas [20].
El método de elementos finitos se considera una herramienta numérica empleada para analizar diseños de ingeniería, en este método se divide una pieza en una gran cantidad de fragmentos de forma simple llamados elementos y se hace un tratamiento matemático determinado en cada uno de éstos en lugar de hacer uno solo sobre un cuerpo de forma compleja; la respuesta de cada elemento es interpolada a la respuesta de todo el conjunto. Generalmente, el análisis de elementos finitos más usado es el de tipo lineal estático y es empleado como herramienta para calcular la resistencia mecánica bajo este tipo de cargas. Este estudio se caracteriza por asumir que los materiales analizados son isotrópicos, homogéneos y continuos. Actualmente, el uso de nuevos algoritmos que representan la estructura ósea con mayor precisión ha permitido construir modelos para calcular cargas en el tejido y las propiedades elásticas de forma [21].

En este punto, conviene indicar que las estructuras giroide, las cuales serán integradas al diseño del vástago de fijación, son superficies mínimas periódicas que se repiten en las tres dimensiones. Las estructuras celulares tipo giroide de Schoen pueden ser modeladas desde el punto de vista matemático a través de la ecuación [1], la cual describe una función matemática de crecimiento tridimensional capaz de mostrar una superficie simétrica, de esta manera conforma una superficie mínima periódica de estructura cubica. Esta representación fue descubierta en 1967 por Luzzati y colaboradores, para la fabricación de una espuma para sistemas de purificación de aguas lipídicas [22].

En la Ecuación [1], a corresponde al valor de la longitud de la celda unitaria, y el parámetro 
J. A. Mina, C. A. Poblano, O. Barceinas, J. Henao, J. Corona

Revista Colombiana de Materiales, ISSN 2256-1013, No 17, pp. 53-71, 2021. http://doi.org/10.17533/udea.rcm.n17a06

$t$ controla el volumen rodeado por la superficie giroide.

$$
\begin{gathered}
\operatorname{Sin}\left(\frac{2 \pi}{a} * x\right) * \operatorname{Cos}\left(\frac{2 \pi}{a} * y\right)+\operatorname{Sin}\left(\frac{2 \pi}{a} * y\right) \\
* \operatorname{Cos}\left(\frac{2 \pi}{a} * z\right)+\operatorname{Sin}\left(\frac{2 \pi}{a} * z\right) \\
* \operatorname{Cos}\left(\frac{2 \pi}{a} * x\right)=t
\end{gathered}
$$

En este trabajo se presenta un protocolo de diseño de un componente tibial empleado en un sistema de reemplazo total de rodilla considerando un sistema de fijación press-fit de estructura celular tipo giroide, empleando herramientas computacionales e información anatómica de un paciente. Se discutirá la obtención de las reconstrucciones tridimensionales, así como los factores críticos del diseño, la selección de la estructura celular giroide, la identificación de algunas propiedades mecánicas del hueso, así como también un análisis simulado del comportamiento de la prótesis en condiciones de trabajo mediante un análisis de elementos finitos.

\section{METODOLOGÍA EXPERIMENTAL}

\subsection{Reconstrucción tridimensional de la tibia}

Se realizó una tomografía computacional de rayos $X$ en un paciente afroamericano de 30 años y $97 \mathrm{~kg}$ de peso sin ningún padecimiento médico empleando un equipo Siemens Healthineers Biograph View CT del laboratorio PET/CT de la Facultad de Medicina de la UNAM. El análisis fue realizado desde la cadera hasta los dedos del pie con una longitud total de $1384,5 \mathrm{~mm}$, a 120 kV y 191 mA y con una separación de placa de $0,6 \mathrm{~mm}$, con lo cual se obtuvieron 4092 imágenes de 512 x 512 pixeles.
Posteriormente, los datos médicos fueron observados empleando el software InVesalius 3.1 (Centro de tecnología e información Renato Archer; Sao Paulo, Brasil), con el fin de realizar una reconstrucción tridimensional basada en la agrupación de vóxels en un rango de atenuación lineal de 226 - 3071 unidades Houndsfield. Para tal fin, fue seleccionada una región de interés y luego se realizó una segmentación de dicha región; posteriormente, la sección fue enmascarada y se obtuvo finalmente la reconstrucción digital de un segmento óseo definido.

Una vez realizada la reconstrucción tridimensional de la tibia, se usó el software de diseño Fusion $360^{\circledR}$ (Autodesk, Inc.) para realizar el diseño del componente, tal como lo muestra la Figura 1. Para el diseño del componente tibial se partió de la reconstrucción tridimensional de la tibia; posteriormente, se realizó un corte en dicha reconstrucción tridimensional llevándose a cabo por encima de la unión con el peroné.

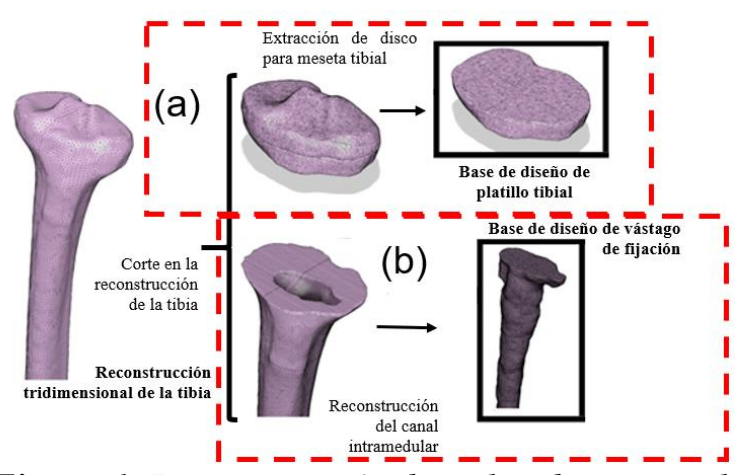

Figura 1. Reconstrucción digital tridimensional de la tibia, segmentos empleados para el diseño del componente.

En la Figura 1a se muestra la cabeza de la tibia, de la cual se extrajo un disco de $10 \mathrm{~mm}$ de espesor, que fue utilizado como base para el diseño del platillo tibial. En la Figura 1b se observa la obtención de la base para el diseño del vástago de fijación a través de la reconstrucción del canal intramedular, con el fin de realizar un empalme con mayor ajuste 
y menor necesidad de remoción de hueso cortical.

\subsection{Determinación de la densidad ósea}

Una vez conocida la morfología ósea, y en consecuencia los requerimientos del sistema de reemplazo, se estableció la densidad ósea aparente del paciente como estrategia para identificar las propiedades mecánicas del hueso y así realizar una verificación posterior del efecto mecánico del componente tibial, una vez es insertado en el hueso y sometido a una carga constante.

Para determinar la densidad aparente ósea del paciente, se realizó una división del segmento de tibia restante en tres zonas: la zona I, con un espesor de $15 \mathrm{~mm}$, corresponde a la zona adyacente al corte y de contacto con la prótesis; la zona intermedia, con $6 \mathrm{~mm}$ de espesor, corresponde al cuello tibial, la zona que rodea la línea epíficial; finalmente, la zona II, con un espesor de $15 \mathrm{~mm}$, corresponde a la parte superior de la diáfisis. La Figura 2 muestra la división realizada sobre la tibia reconstruida. En cada segmento se trazaron líneas equidistantes $(3 \mathrm{~mm}$ de espaciamiento entre cada línea) en los planos axial, coronal y sagital. Los puntos de cada línea están asociados a un valor de atenuación lineal de cada punto por el que pasa, y la convergencia de líneas y puntos sirvió para subdividir la reconstrucción de la tibia en segmentos discretos para la identificación de la densidad. Finalmente, se seleccionó un valor promedio de densidad para las zonas con coeficiente de atenuación linear superior a $1200 \mathrm{HU}$ que corresponde al hueso cortical denso según lo indicado por Misch [1], quien describe los valores de atenuación lineal para identificar el tipo de hueso, como referencias del estado del hueso e incluso para identificar padecimientos [2].
Para la transformación de los valores de atenuación lineal de rayos $\mathrm{X}$ se empleó el método de Yosibash y colaboradores [23]. Éste método permite la conversión a términos de densidad mineral ósea y densidad de ceniza, y consiste en establecer una relación lineal entre el coeficiente de atenuación lineal, la densidad mineral ósea y la densidad de ceniza; los valores de atenuación lineal fueron tomados de los archivos médicos DICOM obtenidos de la tomografía y fueron reemplazados en el modelo matemático expresado en la Ecuación [2].

$\rho=1,22(0.0006822 * H U-0.00548)+0,0523$

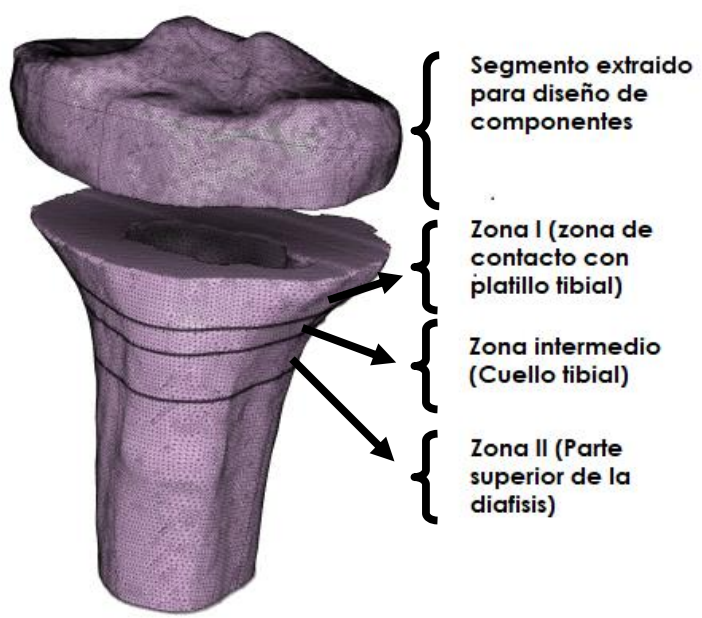

Figura 2. Esquema de zonas de análisis de densidad y características mecánicas del hueso del paciente.

Una vez que se obtuvieron los valores de densidad mineral ósea y de densidad de ceniza, se aplicó el criterio empleado por Shileo y colaboradores [3], quienes utilizaron una correlación lineal para obtener una expresión que permitió expresar la densidad aparente en términos de la densidad de ceniza (Ecuación [3]).

$$
\rho_{\text {aparente }}=1,58 * \rho_{\text {ceniza }}+0,11
$$




\subsection{Cálculo de las propiedades mecánicas del segmento de tibia seleccionado}

Luego de haber establecido la densidad ósea aparente del paciente, se obtuvieron relaciones matemáticas para calcular algunas constantes mecánicas partiendo de una ley constitutiva entre la densidad aparente y las constantes mecánicas; la dirección de las trabéculas en el caso del tejido esponjoso y los canales de Havers del tejido cortical son las direcciones principales dentro del postulado [24]. Bajo este criterio y teniendo en cuenta el bajo grado de anisotropía en los planos coronal y sagital, considerados isotrópicos con respecto al plano axial, se establece un tensor de elasticidad lineal de cuarto orden [25].

Tabla 1. Constante mecánicas para comportamiento isótropo y transversal del tejido óseo a partir de la densidad aparente $(\rho)$ [4].

\begin{tabular}{|c|c|}
\hline \multicolumn{2}{|r|}{ Tejido cortical } \\
\hline $\begin{array}{l}\text { Módulo de } \\
\text { Young plano } \\
\text { transversal }\end{array}$ & $E_{t}=2065 \rho^{3,09}$ \\
\hline $\begin{array}{l}\text { Módulo de } \\
\text { Young plano } \\
\text { isotrópico }\end{array}$ & $E_{p}=2314 \rho^{1,57}$ \\
\hline $\begin{array}{l}\text { Coeficiente de } \\
\text { Poisson }\end{array}$ & $v_{p}=0,3$ \\
\hline $\begin{array}{c}\text { Coeficiente de } \\
\text { Poisson ajustado }\end{array}$ & $\begin{array}{r}v_{p t}=0,0623 \rho^{2}-0,2827 \rho \\
+0,5249\end{array}$ \\
\hline Módulo de Corte & $G_{t}=3892 \rho^{2}-7385 \rho+4606$ \\
\hline \multicolumn{2}{|c|}{$\begin{array}{c}\text { Tejido esponjoso } \\
\end{array}$} \\
\hline $\begin{array}{l}\text { Módulo de } \\
\text { Young plano } \\
\text { transversal }\end{array}$ & $E_{t}=1904 \rho^{1,64}$ \\
\hline $\begin{array}{l}\text { Módulo de } \\
\text { Young plano } \\
\text { isótropo }\end{array}$ & $E_{p}=1157 \rho^{1,78}$ \\
\hline $\begin{array}{l}\text { Coeficiente de } \\
\text { Poisson }\end{array}$ & $v_{p}=0,3$ \\
\hline $\begin{array}{l}\text { Coeficiente de } \\
\text { Poisson ajustado }\end{array}$ & $\begin{aligned} v_{p}=-0,05331 \rho^{4} & +0,1843 \rho^{3} \\
& -0,2438 \rho^{2} \\
& +0,1721 \rho \\
& +0,1675\end{aligned}$ \\
\hline Módulo de Corte & $G_{t}=\frac{1157 \rho^{1,78}}{0,85\left(2\left(1+v_{p}\right)\right)}$ \\
\hline
\end{tabular}

Dado que a escala macroscópica el tejido óseo presenta dos morfologías bien diferenciadas, con porosidades y densidades diferentes, se presentan modelos matemáticos tanto para el tejido cortical como para el tejido esponjoso [26][27]. La Tabla 1 muestra los modelos matemáticos empleados en este trabajo para la identificación de las constantes mecánicas.

\subsection{Fabricación de estructuras celulares giroide simple y cálculo de densidad}

Se realizó un estudio para evaluar la densidad aparente de estructuras celulares giroides en función del cambio del tamaño de celda y del cambio en el valor del parámetro $t$. Para este estudio se imprimieron muestras cúbicas de estructura giroide mediante la técnica DMLS (Direct Metal Laser Sintering) usando polvos de aleación Ti6Al4V, según las condiciones indicadas por el proveedor del equipo de impresión 3D (EOSINT M280). Una vez impresas las muestras, se procedió a calcular su densidad volumétrica, conociendo las dimensiones del diseño tridimensional base de la impresión; se calculó el volumen aparente. El cálculo de la densidad aparente se realizó a partir de la masa y la densidad volumétrica siguiendo la metodología reportada por Corona y colaboradores [5].

Una vez conocida la densidad volumétrica, se establecieron correlaciones en función del parámetro $\mathrm{t}$ y del tamaño de celda para determinar la densidad de la estructura en función de dichas variables de diseño, los valores de densidad de las estructuras fueron comparados con el valor promedio del hueso trabecular de la tibia del paciente; la comparación se realizó con el fin de seleccionar la estructura giroide para el vástago de fijación del componente tibial con la densidad más parecida a la del hueso trabecular promedio del paciente. 
J. A. Mina, C. A. Poblano, O. Barceinas, J. Henao, J. Corona

Revista Colombiana de Materiales, ISSN 2256-1013, No 17, pp. 53-71, 2021. http://doi.org/10.17533/udea.rcm.n17a06

\subsection{Diseño de prótesis}

Una vez establecida la densidad ósea aparente del paciente, se realizó la reconstrucción del hueso trabecular que sirvió como base para el diseño del vástago de fijación; la metodología, consistió en la extracción de un disco de $10 \mathrm{~mm}$ para la construcción del platillo tibial, en la parte superior se hizo una hendidura para el empalme con un componente intermedio. Por otra parte, para el diseño del vástago de fijación, se partió de la reconstrucción del canal intramedular, pasando por los cortes longitudinal y transversal que dan forma al sistema press-fit y a la longitud del vástago y se finalizó con la integración de la estructura celular en el cuerpo del vástago.

\subsection{Análisis de respuesta mecánica del sistema tibia-componente tibial en condiciones de compresión mediante análisis de elementos finitos}

Conociéndose las propiedades mecánicas del hueso y definido el modelo de reemplazo para el componente tibial, se realizó una evaluación mecánica en condiciones simuladas para identificar la posible respuesta mecánica en condiciones de compresión. Basado en un trabajo realizado por Quilez y colaboradores [28], se desarrolló una evaluación simulada, por elementos finitos, de compresión aplicando una carga distribuida sobre la platillo tibial del componente de reemplazo en tres condiciones diferentes para considerar el ciclo de caminata: en el primer caso, la carga fue vertical y se encontraba equitativamente distribuida por dos cóndilos tibiales; en el segundo caso, la reacción de carga en la articulación fue distribuida a través de la zona medial y lateral en una relación de $70 \%$ y $30 \%$ respectivamente. El tercer caso correspondió a una reacción de carga distribuida de $30 \%$ y $70 \%$ [28].
El análisis permitió encontrar los valores del esfuerzo equivalente y de deformación equivalente en el sistema hueso-componente tibial, haciendo uso de componentes tibiales con vástago de fijación de estructura sólida y otro con vástago de fijación de estructura celular giroide; en este estudio también se analizó el efecto de emplear un componente tibial con el vástago de fijación de estructura sólida.

Para el análisis de elementos finitos se emplearon como condiciones de frontera los valores de las propiedades físicas y mecánicas de la aleación Ti6Al4V procesada mediante técnicas de manufactura aditiva almacenadas en el software ANSYS 19.1; además, se utilizaron las propiedades físicas y mecánicas calculadas en el tejido adyacente al corte y contacto con la prótesis (zona I), donde se tuvieron en cuenta los valores promedio de densidad del segmento lateral y medial de dicha zona, el coeficiente de fricción promedio, la resistencia a la compresión y el módulo de Young en la zona mencionada y calculada a partir de la tomografía computacional de rayos $\mathrm{X}$.

Para el caso de las simulaciones de los pares componente tibial-hueso en los que se tuvo en cuenta vástagos de fijación de estructura celular giroide, se consideraron valores de densidad calculados previamente, así como el módulo de Young, coeficiente de Poisson y resistencia a la compresión; los últimos tres valores fueron obtenidos a partir de ensayos de compresión sobre la estructura celular seleccionada.

Las condiciones de frontera para dicho análisis consistieron en los valores de densidad y respuesta mecánica tanto de las estructuras tipo giroide como del hueso de la tibia, también se tuvieron en cuenta algunas constantes para la aleación de titanio 
guardadas en la base de datos del software. Las condiciones de carga utilizadas para la simulación son mostradas en la Figura 3. A través del software ANSYS 19.1 se realizaron los análisis de elementos finitos para estimar el comportamiento de la tibia en condición de compresión. Para este análisis se realizaron dos mallados independientes; el primero sobre el componente de reemplazo empleando un método de elementos tetraédricos, con un rango de tamaños entre 2 y $4 \mathrm{~mm}$. Por otra parte, el segundo fue desarrollado sobre la reconstrucción tridimensional del hueso empleando también tetraedros, pero con un rango de tamaños entre 2 y $6 \mathrm{~mm}$.

Es importante mencionar que la versión del software ANSYS empleada en este trabajo presenta dificultades para las condiciones de mayado de las estructuras celulares, razón por la cual se optó por emplear una estructura sólida a la cual se le atribuyó las propiedades mecánicas en condiciones de compresión de la estructura celular giroide seleccionada. Lo anterior, con el fin de tener una aproximación del comportamiento mecánico del componente tibial de vástago celular giroide en condiciones de trabajo.

Por otra parte, las cargas empleadas para la simulación fueron aplicadas sobre el platillo tibial; para ello, la cara superior fue dividida en dos secciones y para la distribución de las cargas totales en cada segmento de la cara superior del platillo tibial se tuvo en cuenta la metodología desarrollada por Quilez y colaboradores [28]. Las cargas totales fueron de 3000, 2000 y $900 \mathrm{~N}$ distribuidas en 50\%$50 \%, 70 \%-30 \%$ y $30 \%-70 \%$ en los dos sistemas del conjunto componente tibialhueso, tal como se puede ver en la Figura 3.

Finalmente, es necesario mencionar que en la simulación se consideró un soporte fijo o estático en la parte inferior del segmento de tibia que tuvo una longitud de $200 \mathrm{~mm}$. Dentro de las restricciones de la simulación se tuvo en cuenta el contacto que ocurre entre el platillo tibial y la tibia, así como también el contacto del vástago de fijación con la zona interna del tejido cortical de la tibia; en estas zona se consideró un coeficiente de fricción entre el par hueso-metal de 0,7; según lo indicado por Dammak y colaboradores [6].

La Figura 3 muestra la forma como fueron aplicadas las cargas, sobre la superficie del platillo tibial, dicha superficie fue dividida en dos secciones para aplicar las cargas sobre toda la superficie superior del componente tibial.

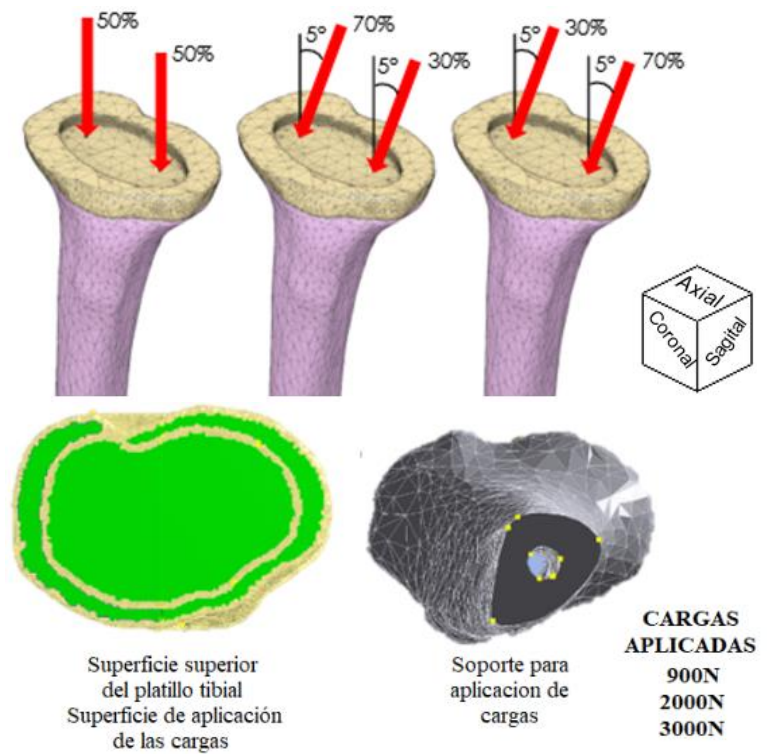

Figura 3. Condiciones de carga en la zona medial y latera del platillo tibial.

Teniendo en cuenta que el criterio de la densidad de energía de deformación, atribuida a von Mises, establece que la fluencia inicia cuando dicha densidad de energía en un punto es igual a la densidad de energía de deformación de una prueba uniaxial en tensión o compresión, el esfuerzo y deformación equivalentes (conocidos también como esfuerzo y deformación de von Mises) fueron considerados como criterios 
J. A. Mina, C. A. Poblano, O. Barceinas, J. Henao, J. Corona

Revista Colombiana de Materiales, ISSN 2256-1013, No 17, pp. 53-71, 2021. http://doi.org/10.17533/udea.rcm.n17a06

para caracterizar el sistema componente tibial-tibia.

\section{RESULTADOS Y ANÁLISIS}

A la reconstrucción digital tridimensional se le sustrajo una parte para la construcción de los componentes de la prótesis, al segmento restante le fue evaluado el coeficiente de atenuación en los planos axial, transversal y coronal para conocer la variación de la densidad ósea del paciente. La Figura 4 muestra un histograma promedio con el cambio en los coeficientes de atenuación lineal y el tipo de hueso presente en las diferentes zonas analizadas.

En ese orden de ideas, es posible observar que la densidad del tejido cortical aumenta en función de la distancia entre la zona de resección (zona de corte donde se realizaría la inserción del componente tibial) y el cuello tibial, debido a la mayor concentración de esfuerzos en el hueso por efecto de las cargas aplicadas en compresión.

De los picos característicos de cada zona, incluidos en el histograma de la Figura 4, se seleccionaron segmentos de cada uno para establecer un valor promedio de densidad en cada zona. Para la selección de los datos alrededor de los picos, se utilizó como referencia el rango de atenuación lineal característico de los tipos de hueso identificados en el histograma. De esta manera, para los picos de la zona I, (zona de contacto entre el platillo tibial y hueso) se promediaron todos los valores del segmento de curva que registraron un valor de atenuación entre 350-850HU; Para la zona intermedia, que presentó picos en $1035 \mathrm{HU}$ y en $1545 \mathrm{HU}$, los valores adyacentes a cada pico fueron los que pertenecían a los rangos de atenuación de $859-1250 \mathrm{HU}$ y $>1250 \mathrm{HU}$. Los valores de densidad promedio para cada zona se encuentran en la Tabla 2 y fueron empleados para realizar los calculos posteriores.

Una vez convertidos los valores de atenuación lineal de rayos $\mathrm{X}$ promedio de las zonas seleccionadas, se calculó el valor del módulo de Young en el plano transversal y en el plano axial.

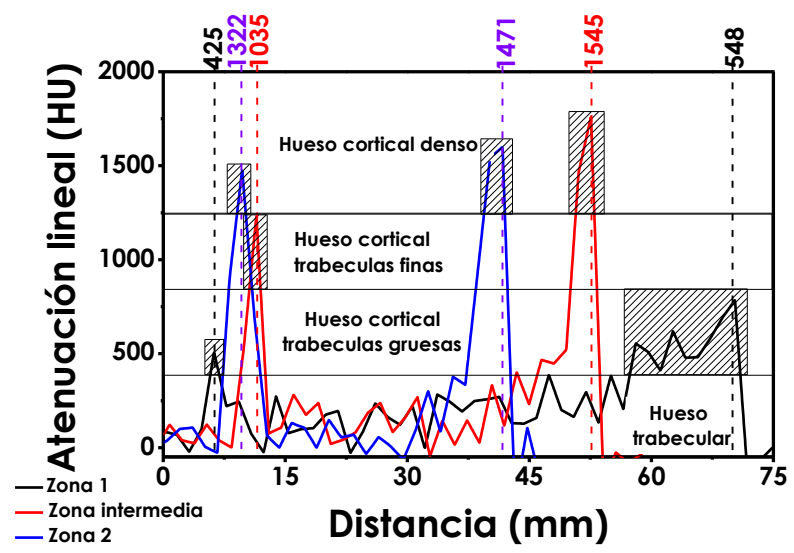

Figura 4. Valores de atenuación linear de rayos $X$ en segmentos de la tibia del paciente.

El coeficiente de Poisson y el módulo de corte, para el tejido cortical y para el tejido esponjoso, se calcularon a través del uso de las expresiones matemáticas mencionadas con anterioridad en la Tabla 1, aplicados a la parte superior de la tibia.

La Tabla 2 y la Tabla 3 muestran que las constantes mecánicas del hueso cambian dependiendo del tipo de tejido y de la zona analizada, esto puede ser explicado debido a la naturaleza ortotrópica del hueso que permite que las propiedades mecánicas varíen en cada uno de los ejes de referencia, precisamente por la diferencia en la densidad del hueso desde el exterior hacia el interior. Hay que reconocer que los valores de densidad ósea aparente de cada persona pueden variar dependiendo de aspectos básicos como la alimentación, la edad, la actividad física, el grupo étnico, el género, entre otros [29]. 
Tabla 2. Densidad ósea aparente, módulo de Young y coeficiente de Poisson del hueso del paciente obtenidas a partir de modelos matemáticos incluidos en la Tabla 1. Otros autores definieron los valores para el Módulo de Young [30] [31].

\begin{tabular}{|c|c|c|c|c|c|c|c|c|c|}
\hline Zona & $\begin{array}{c}\text { I } \\
\text { (Lateral) }\end{array}$ & $\begin{array}{c}\text { I } \\
\text { (Medial) }\end{array}$ & $\begin{array}{c}\text { I } \\
\text { (Central) }\end{array}$ & $\begin{array}{c}\text { Intermedia } \\
\text { (Lateral) }\end{array}$ & $\begin{array}{c}\text { Intermedia } \\
\text { (Medial) }\end{array}$ & $\begin{array}{c}\text { Intermedia } \\
\text { (Central) }\end{array}$ & $\begin{array}{c}\text { II } \\
\text { (Lateral) }\end{array}$ & $\begin{array}{c}\text { II } \\
\text { (Medial) }\end{array}$ & $\begin{array}{c}\text { II } \\
\text { (Central) }\end{array}$ \\
\hline Clasificación & $\begin{array}{l}\text { Cortical } \\
\text { de } \\
\text { trabéculas } \\
\text { gruesas }\end{array}$ & $\begin{array}{c}\text { Cortical } \\
\text { de } \\
\text { trabéculas } \\
\text { gruesas }\end{array}$ & Trabecular & $\begin{array}{c}\text { Cortical } \\
\text { denso }\end{array}$ & $\begin{array}{c}\text { Cortical } \\
\text { poroso de } \\
\text { trabéculas } \\
\text { finas }\end{array}$ & Trabecular & $\begin{array}{c}\text { Cortical } \\
\text { denso }\end{array}$ & $\begin{array}{c}\text { Cortical } \\
\text { denso }\end{array}$ & Trabecular \\
\hline $\begin{array}{c}\text { Tipo de hueso }(\mathrm{D}= \\
\text { Density })\end{array}$ & D3 & D3 & D4 & D1 & D2 & D4 & D1 & D1 & D4 \\
\hline $\begin{array}{c}\text { Coeficiente de } \\
\text { atenuación } \\
{[\mathrm{HU}]}\end{array}$ & 425 & 548 & 342 & 1035 & 1545 & 345 & 1322 & 1470 & 280 \\
\hline $\begin{array}{c}\text { Densidad ósea } \\
\text { aparente } \\
{\left[\mathrm{g} / \mathrm{cm}^{3}\right]}\end{array}$ & 0,80 & 0,97 & 0,70 & 1,61 & 2,28 & 0,70 & 1,98 & 2,18 & 0,61 \\
\hline $\begin{array}{c}\text { Módulo de Young } \\
\text { (Plano transverso) } \\
{\left[\mathbf{N} / \mathbf{m m}^{2}\right]}\end{array}$ & 1055,39 & 1858,61 & 672,70 & 8941,90 & 26272,50 & 684,55 & 17160,70 & 22913,63 & 855,75 \\
\hline $\begin{array}{c}\text { Módulo de Young } \\
\text { (Plano de isotropía) } \\
{\left[\mathbf{N} / \mathbf{m m}^{2}\right]}\end{array}$ & 1645,32 & 2193,45 & 1308,79 & 4872,68 & 8425,40 & 1320,47 & 6785,96 & 7859,71 & 485,70 \\
\hline $\begin{array}{c}\text { Coeficiente de } \\
\text { Poisson (Ajustado) }\end{array}$ & 0,34 & 0,31 & 0,36 & 0,23 & 0,20 & 0,36 & 0,21 & 0,20 & 0,22 \\
\hline
\end{tabular}

Tabla 3. Módulo de corte y esfuerzo de compresión del hueso del paciente obtenidos a partir de modelos matemáticos incluidos en la Tabla 1 [32] [33].

\begin{tabular}{|c|c|c|c|c|c|c|c|c|c|}
\hline Zona & $\begin{array}{c}\text { I } \\
\text { (Lateral) }\end{array}$ & $\begin{array}{c}\text { I } \\
\text { (Medial) }\end{array}$ & $\begin{array}{c}\text { I } \\
\text { (Central) }\end{array}$ & $\begin{array}{c}\text { Intermedia } \\
\text { (Lateral) }\end{array}$ & $\begin{array}{c}\text { Intermedia } \\
\text { (Medial) }\end{array}$ & $\begin{array}{c}\text { Intermedia } \\
\text { (Central) }\end{array}$ & $\begin{array}{c}\text { II } \\
\text { (Lateral) }\end{array}$ & $\begin{array}{c}\text { II } \\
\text { (Medial) }\end{array}$ & $\begin{array}{c}\text { II } \\
\text { (Central) }\end{array}$ \\
\hline $\begin{array}{c}\text { Densidad ósea } \\
\text { aparente } \\
{\left[\mathrm{g} / \mathrm{cm}^{3}\right]}\end{array}$ & 0,80 & 0,97 & 0,70 & 1,61 & 2,28 & 0,70 & 1,98 & 2,18 & 0,61 \\
\hline $\begin{array}{c}\text { Esfuerzo de } \\
\text { compresión } \\
\text { (Dirección axial) } \\
{\left[\mathbf{N} / \mathbf{m m}^{2}\right]} \\
\end{array}$ & 48,13 & 67,91 & 36,59 & 176,60 & 340,24 & 36,98 & 262,57 & 313,07 & 16,23 \\
\hline $\begin{array}{c}\text { Esfuerzo de } \\
\text { compresión } \\
\text { (Dirección transversal) } \\
{\left[\mathbf{N} / \mathbf{m m}^{2}\right]}\end{array}$ & 26,65 & 35,14 & 21,39 & 75,73 & 128,23 & 21,57 & 104,13 & 119,94 & 10,97 \\
\hline $\begin{array}{c}\text { Módulo de corte } \\
\text { (Plano transverso) } \\
{\left[\mathbf{N} / \mathbf{m m}^{2}\right]}\end{array}$ & 1183,47 & 1104,00 & 1352,17 & 2788,71 & 7975,10 & 1344,45 & 5276,59 & 6992,82 & 219,77 \\
\hline $\begin{array}{c}\text { Módulo de corte } \\
\text { (Plano transverso) } \\
{\left[\mathbf{N} / \mathbf{m m}^{2}\right]}\end{array}$ & 632,82 & 843,63 & 503,38 & 1874,11 & 3240,54 & 507,87 & 2609,98 & 3022,96 & 315,70 \\
\hline
\end{tabular}

Sin embargo, vale la pena mencionar que los resultados mostrados en la Tabla 2 y la Tabla 3 son congruentes con estudios realizados por otros autores [30], [31], [32] y [33].

La determinación de la relación masavolumen de las estructuras tipo giroide simple fue de vital importancia como criterio de diseño del vástago de sujeción del componente tibial, ya que como se discutió en parágrafos anteriores, la estructura celular del vástago de fijación simulará la densidad de la estructura ósea del hueso trabecular de la tibia del receptor. En ese orden de ideas, conocer los valores de densidad permitió identificar la configuración de parámetros de celda para emular la densidad del hueso receptor.

La Figura 5 muestra cómo los cambios en el tamaño de celda y en el parámetro $t$, que 
controla el espesor de pared de la estructura, afectan la relación relativa entre masa y volumen; por una parte, en la Figura 5a se puede observar una relación de inversa proporcionalidad del parámetro $t$ y la densidad relativa para el caso de las estructuras tipo giroide simple, lo cual puede ser explicado ya que un aumento en dicho parámetro sugiere un aumento en el diámetro de las oquedades de la estructura celular acompañado de un adelgazamiento de las paredes de dicha estructura.

Por otra parte, en el caso de la relación tamaño de celda-densidad, se pudo observar un leve aumento de dicha propiedad física en función del aumento del tamaño de celda; esta relación de proporcionalidad puede ser explicada ya que el incremento del tamaño de celda sugiere un incremento en el volumen, así como un aumento en la masa lo cual repercute directamente en el resultado de la relación masa/volumen relativo y así un aumento en la densidad.

Es importante mencionar que ambas gráficas en la Figura 5 muestran que la densidad de la estructura tipo giroide simple coincide con el rango de densidad ósea aparente del paciente en la zona central del hueso (zonas rectangulares punteadas), i.e. 0,61 - 0,77 $\mathrm{g} / \mathrm{cm}^{3}$, según lo mostrado en los resultados incluidos en la Tabla 2.

Luego de comparar los valores de densidad relativa en función del parámetro $t$ y en función del tamaño de celda con el valor promedio del rango de densidad ósea aparente del hueso trabecular, se puede concluir que la combinación de parámetros de diseño de la estructura giroide simple permite garantizar una densidad en dicha estructura similar a la densidad aparente del hueso trabecular. Estos parámetros corresponden a un tamaño de celda de $4 \mathrm{~mm}$ con un $t$ de 0,7 .

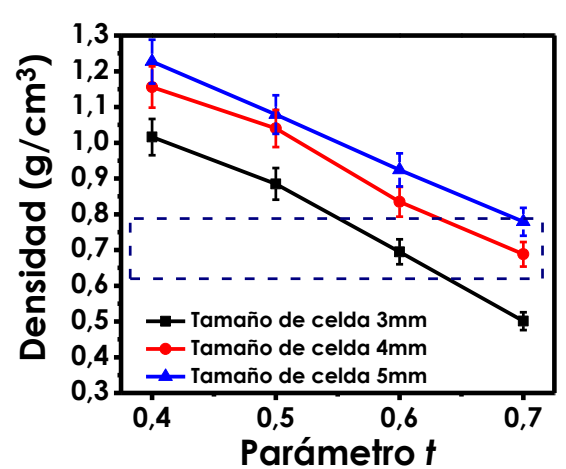

(a)

(b)

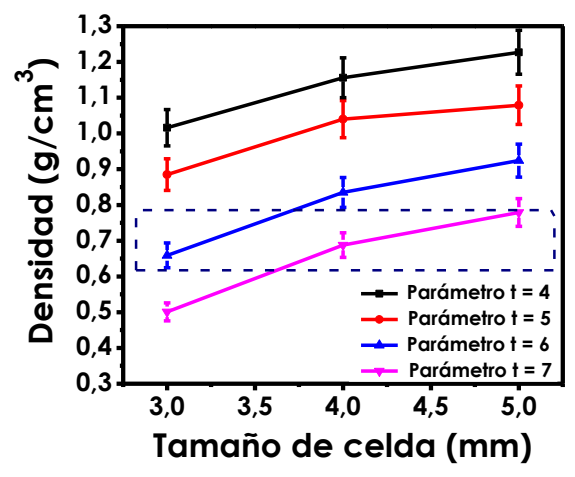

Figura 5. Variación en la densidad de estructuras giroide simple fabricadas por medio de la técnica DMLS usando polvos de Ti6Al4V

de acuerdo con: (a) el parámetro ty $(b)$ el tamaño de celda.

A continuación, en la Figura 6 se muestra la reconstrucción del hueso trabecular y la conversión al vástago de fijación de estructura celular tipo giroide simple. La Figura 6 presenta un esquema del paso a paso para el procedimiento de diseño del vástago de fijación. Una vez diseñado el vástago de fijación, éste se adicionó al platillo tibial para constituir una sola pieza del componente tibial del sistema de reemplazo. En la Figura 7 se muestra el procedimiento de diseño del platillo tibial y el diseño final del componente tibial para un sistema de reemplazo total de rodilla; además, se muestra un diseño de componente tibial de vástago de fijación de $30 \mathrm{~mm}$ de longitud con estructura celular tipo giroide simple. 

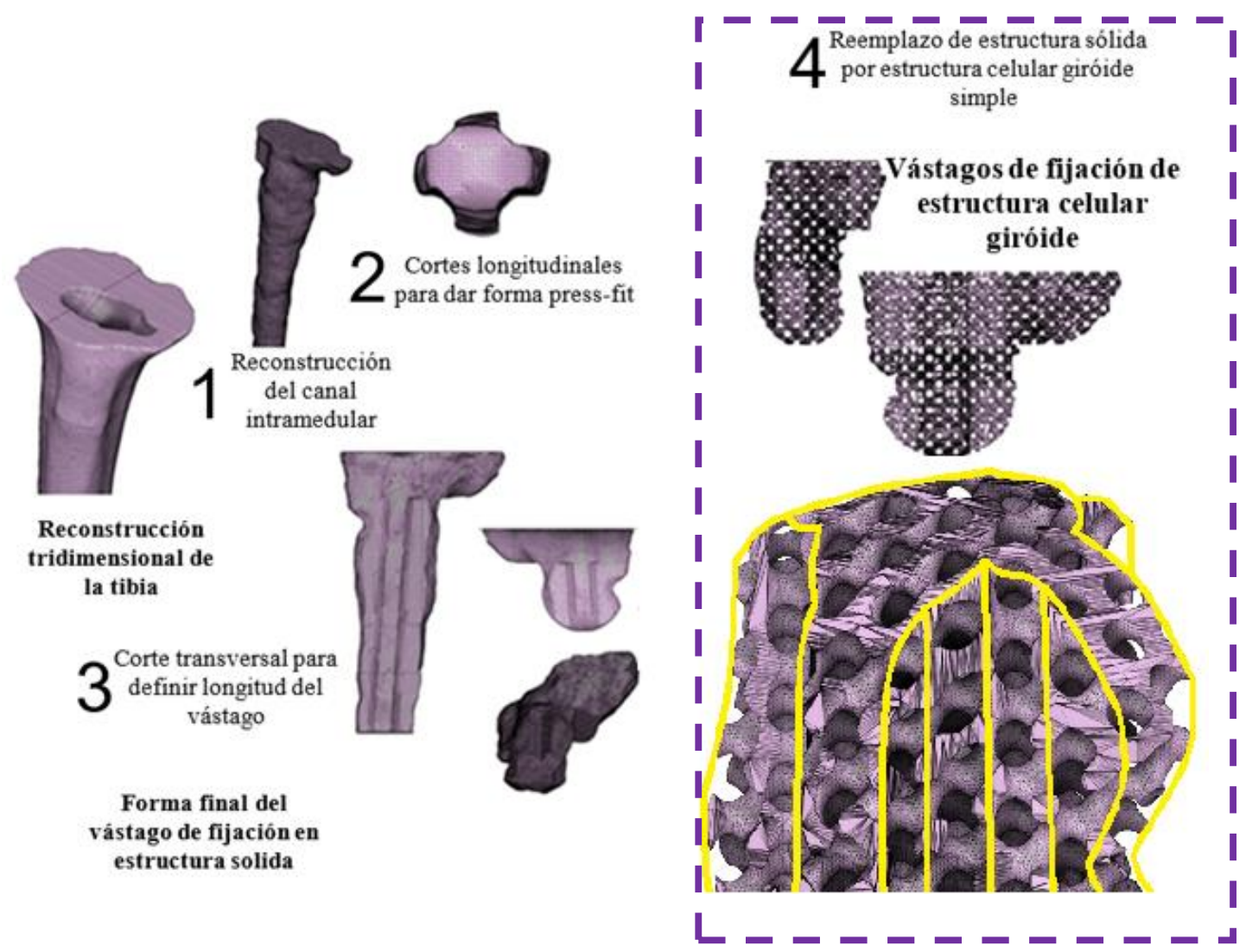

Figura 6. Reconstrucción digital y diseño de vástago de fijación press-fit para prótesis de rodilla.

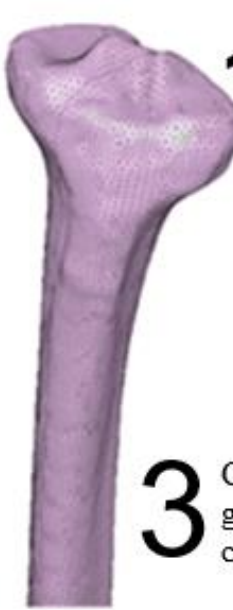

Corte de la parte superior de la reconstrucción de la tibia

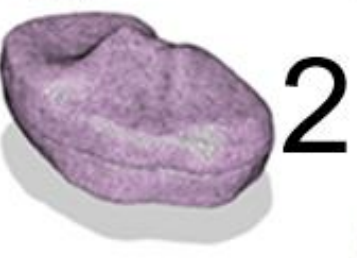

Crear una hendidura que garantice el empalme con el componente intermedio

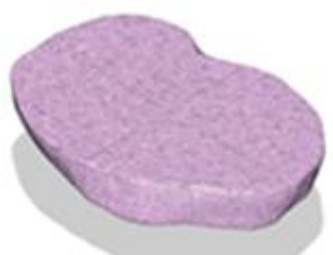

Dividir el cuerpo extrayendo un disco de $10 \mathrm{~mm}$ de espesor

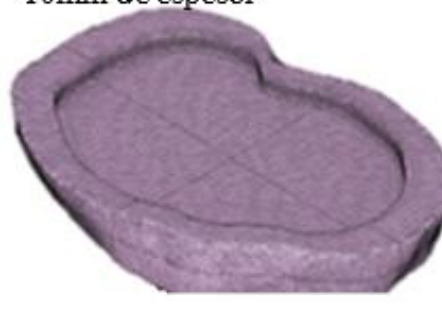

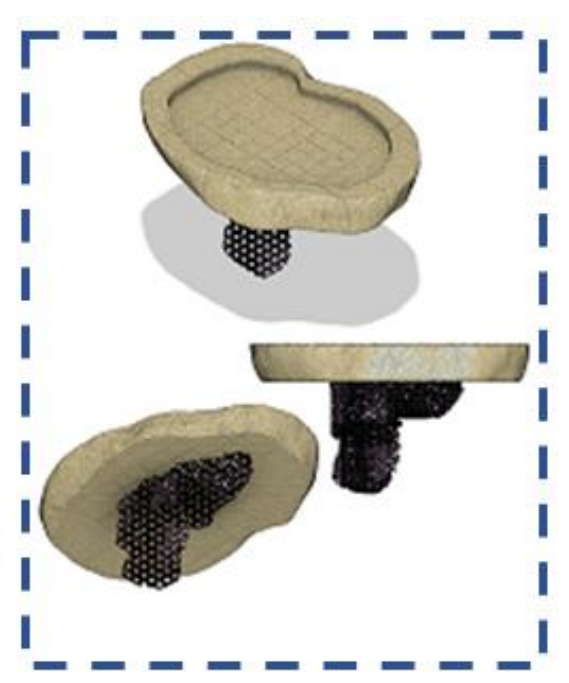

Figura 7: Diseño de platillo tibial y diseño del componente tibial de la prótesis. 
J. A. Mina, C. A. Poblano, O. Barceinas, J. Henao, J. Corona

Revista Colombiana de Materiales, ISSN 2256-1013, No 17, pp. 53-71, 2021. http://doi.org/10.17533/udea.rcm.n17a06

Los análisis de elementos finitos realizados al par mecánico tibial-componente tibial fueron realizados teniendo en cuenta como condiciones de frontera los valores mostrados a continuación.

Tabla 4. Condiciones de frontera para análisis de elementos finitos.

\begin{tabular}{|c|c|}
\hline \multicolumn{2}{|c|}{$\begin{array}{l}\text { Propiedades del hueso calculadas a partir } \\
\text { de la tomografía computacional de rayos } \mathrm{X}\end{array}$} \\
\hline Densidad del hueso & $0,89 \mathrm{~g} / \mathrm{cm} 3$ \\
\hline $\begin{array}{l}\text { Coeficiente de } \\
\text { fricción }\end{array}$ & 0,32 \\
\hline $\begin{array}{l}\text { Resistencia a la } \\
\text { compresión }\end{array}$ & $30,9 \mathrm{MPa}$ \\
\hline Módulo de Young & $1919,38 \mathrm{MPa}$ \\
\hline \multicolumn{2}{|c|}{ Propiedades de la estructura celular giroide } \\
\hline Densidad & $0,71 \mathrm{~g} / \mathrm{cm} 3$ \\
\hline Módulo de Young & $737,19 \mathrm{MPa}$ \\
\hline $\begin{array}{l}\text { Coeficiente de } \\
\text { Poisson }\end{array}$ & 0,29 \\
\hline $\begin{array}{l}\text { Resistencia a la } \\
\text { compresión }\end{array}$ & $33,66 \mathrm{MPa}$ \\
\hline
\end{tabular}

La Figura 8 muestra los valores de esfuerzo equivalente promedio y de deformación equivalente de los sistemas de platillo tibialhueso, calculado a partir del método de elementos finitos, para las tres diferentes distribuciones de carga. Los resultados de estos análisis apuntan a que la distribución de carga equitativa ( $50 \%$ medial $-50 \%$ lateral), que corresponde a una posición de pie en condición estática, es decir el paciente de pie sin moverse, ofrece el mayor valor de esfuerzo y deformación equivalentes, seguido por la distribución 30-70\% que corresponde a la fase impulso de talón en el ciclo de marcha, donde la distribución de la carga se inclina hacia la zona medial del sistema esquelético. Finalmente, el nivel más bajo de energía de deformación se presentó en la distribución de 70-30\% que corresponde a la fase de golpe de talón donde la distribución de carga se inclina hacia el componente lateral.
El sistema con vástago de fijación celular simulado presenta menor deformación y esfuerzo equivalente que el sistema con vástago de fijación de estructura sólida, lo cual implica que hay una menor generación de energía de deformación en el sistema con estructura celular, lo que implica un efecto menos nocivo en el hueso usando una estructura de este tipo. En el caso de los esfuerzos equivalentes, es posible indicar que una menor concentración de esfuerzos en las zonas de contacto con los tejidos óseos permitirá disminuir la probabilidad de blindaje de esfuerzos o aflojamiento aséptico.

Los niveles de deformación equivalente muestran que, en cualquiera de las distribuciones de carga empleadas, la deformación en el hueso y en el componente tibial de la prótesis se encuentran entre 0,0083 $-0,0156 \mathrm{~mm} / \mathrm{mm}$ para el caso del vástago de estructura sólida y $0,0075-0,016 \mathrm{~mm} / \mathrm{mm}$ para el vástago de estructura celular giroide. Comparando los resultados mostrados en la Figura 8 se puede observar que, tanto los valores de esfuerzo equivalente promedio como los valores de deformación equivalente promedio son similares, sin importar la estructura del vástago de fijación; esto demuestra que la utilización de una estructura celular no disminuye la respuesta mecánica de vástago de fijación, por el contrario, podría beneficiar el funcionamiento del componente tibial ya que con una estructura celular la pieza es más ligera y con una densidad y estructura similar a la del hueso receptor.

La Figura 9 muestra las zonas de maxima y minima concentracion de esfuerzos en el sistema componente tibial-tibia en el plano axial coronal y sagital; puede observarse el cambio en la concentracion de esfuerzos equivalentes como efecto del cambio en la distribucion de cargas. Es importante mencionar que el valor del esfuerzo equivalente máximo alcanzado por los 
sistemas tibia-componente tibial obtenido fue de hasta $30 \mathrm{MPa}$; dicho valor fue comparado con el valor del esfuerzo de cedencia del hueso en la zona de contacto calculado en el paciente $(60,80 \mathrm{MPa})$ y por el reportado por Elise y colaboradores $(115,06$ $\mathrm{MPa}$ [34].
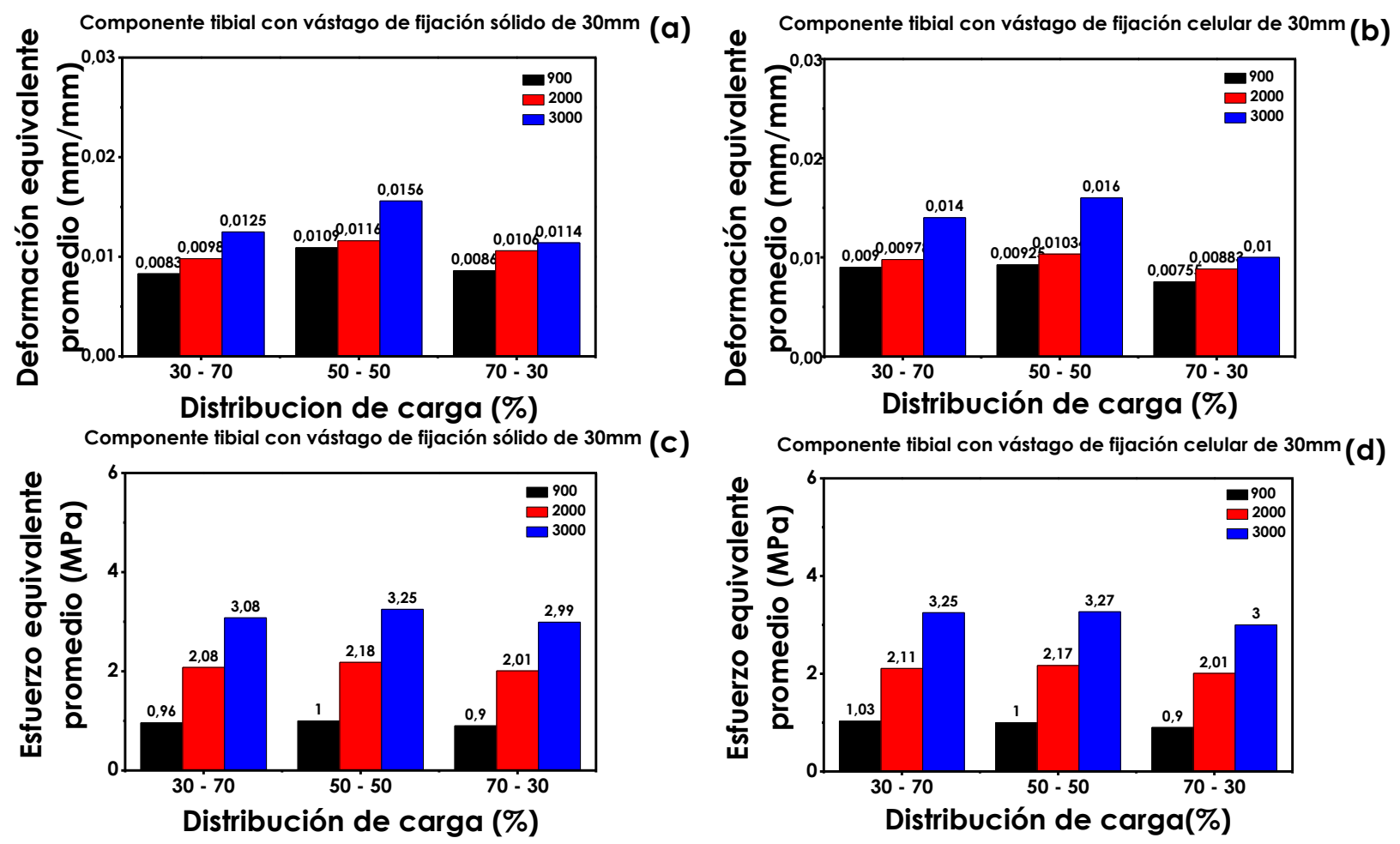

Figura 8. Esfuerzo equivalente y deformación equivalente del sistema tibia-componente tibial en función de la distribución de carga y valor total de carga total; (a) y (b) corresponden a la deformación equivalente en función de la distribución de carga para vástagos de estructura sólida y giroide respectivamente, (c) y (d) corresponden a esfuerzos equivalentes en función de la de la distribución de carga para vástagos de estructura sólida y giroide respectivamente.

Se pudo observar que el componente tibial diseñado ofrece un valor de esfuerzo equivalente muy inferior al valor del esfuerzo de cedencia del hueso cortical de la tibia en condiciones de compresión; lo cual implica una energía de deformación baja y por lo tanto, un menor riesgo daño en la estructura ósea.

Lo que se buscó a través de este diseño con geometría anatómica y vástago de estructura celular, fue utilizar una estructura de características morfológicas similares a las del hueso trabecular, con el fin de obtener una mejor interacción hueso-prótesis, una disminución en la cantidad de material empleado en la fabricación del componente tibial y la disminución del peso de dicho elemento; además de la posibilidad de aportar a una menor concentración de esfuerzos y una mejor distribución de los mismos, para evitar efectos adversos como el blindaje de esfuerzos y el aflojamiento aséptico, como consecuencia del debilitamiento del hueso. 
La vista axial de la Figura 9a y Figura 9b muestra los esfuerzos equivalentes sobre el platillo tibial y sobre la zona de contacto entre el componente de la protesis y la tibia. En estas zonas los esfuerzos equivalentes promedio se encuentran en el rango de 2 a 6 MPa. Revisando las vistas coronal y sagital de la Figura 9a y Figura 9b, es posible observar el esfuerzo equivalente que se concentra en la interfaz hueso-protesis; tambien se observa que no hay concentración de esfuerzos (calculados entre 26 y $120 \mathrm{MPa}$ ) que sea comparable con la resistencia a la compresion del hueso y que ponga en riesgo la integridad de éste último.

(a)

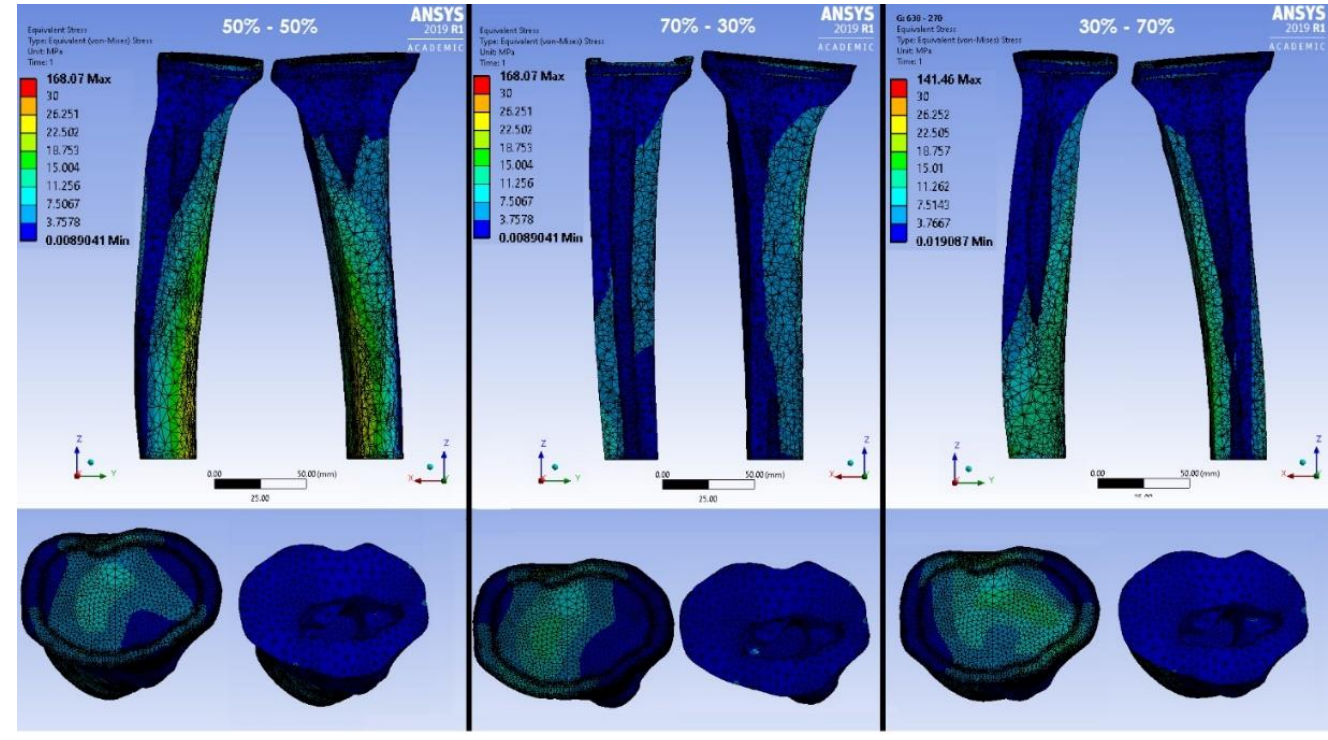

(b)

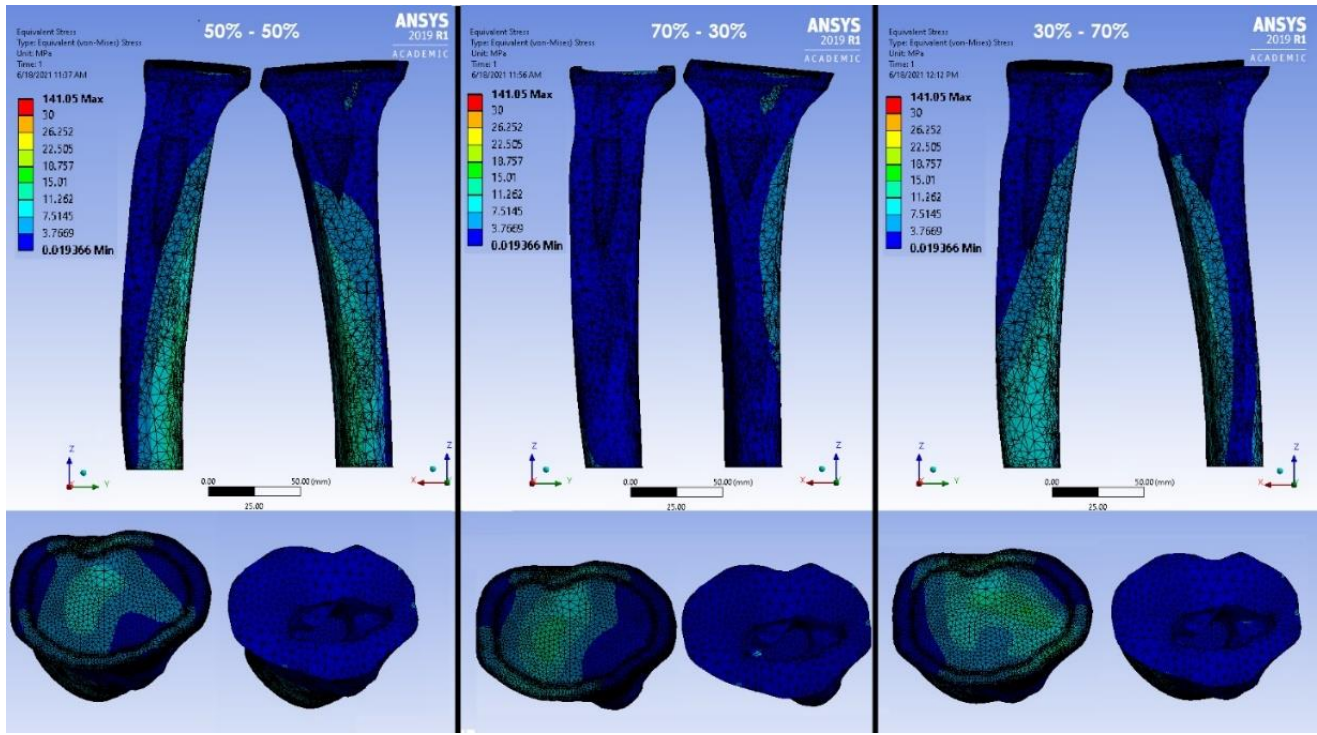

Figura 9. Modelación de los esfuerzos equivalentes y su efecto en el sistema en función de las distribuciones de carga aplicadas (a) componente tibial de estructura celular giroide (b) componente tibial de estructura sólida. 
J. A. Mina, C. A. Poblano, O. Barceinas, J. Henao, J. Corona

Revista Colombiana de Materiales, ISSN 2256-1013, No 17, pp. 53-71, 2021. http://doi.org/10.17533/udea.rcm.n17a06

Sin embargo, hay que aclarar que para desarollar las simulaciones se estableció un soportes estatico en la cara transversal de la zona inferior de reconstrucción tridimensional de la tibia, tal como se muestra en la Figura 3 en esta zona se presentaron niveles superiores de esfuerzos equivalentes en comparación con los valores promedio; lo anterior se debe a que dicho soporte corresponde a una cara de la reconstrucción que restrinje el movimiento y donde las caracteristicas del hueso son interrumpidas y se reemplaza por valores de resistencia y rigidez infinitos.

\section{CONCLUSIONES}

El uso de tomografías computacionales de rayos $\mathrm{X}$ y de herramientas computacionales, así como la inclusión de estructuras tipo giroide para emular la densidad ósea de un paciente en una prótesis permitieron diseñar un componente tibial con una morfología anatómica congruente con las características densimétricas y morfológicas particulares del paciente. El diseño realizado y evaluado en condiciones de compresión por simulación computacional, genera un esfuerzo de deformación inferior al esfuerzo de cedencia del hueso cortical de la tibia, lo cual sugiere que el diseño propuesto en el presente trabajo puede promover un bajo grado de afectación al hueso en condiciones de carga mecánica en condiciones de compresión altas y bajas.

La integración de la morfología anatómica del hueso del paciente permitió diseñar un componente en el que se alcanzara valores de esfuerzos equivalentes y energía de deformación considerablemente bajos teniendo en cuenta las propiedades mecánicas calculadas del hueso. Es importante reconocer que el componente tibial de vástago de estructura celular mostró una menor concentración de energía de deformación que el componente tibial de estructura sólida, garantizando así un menor efecto nocivo en el hueso.

Los bajos niveles de energía de deformación presentados en cada distribución de carga, es decir, 30-70\%; 50-50\% y 70-30\%, del sistema tibia-componente tibial, obtenidos en el presente estudio sugieren un bajo nivel de concentración de esfuerzos en el hueso, así como una distribución homogénea de las cargas en la prótesis y el tejido óseo circundante.

\section{AGRADECIMIENTOS}

Los autores agradecen a Programa de Becas Nacionales de CONACYT por el apoyo brindado en el proyecto. Agradecimientos al programa de posgrados de CIATEQ AC y al PICYT (Posgrado Interinstitucional en Ciencia y Tecnología) por el apoyo a la realización del presente trabajo. Dr. John Henao agradece al programa de cátedras CONACYT, proyecto 848 .

\section{REFERENCIAS}

[1] LENS.ORG, «The Lens - Free and open patent and scholary search,» [En línea]. Available:

https://www.lens.org/lens/search?n=10\&q=( Knee\%20Prosthesis)\%20AND\%20classifica tion_cpc:(A*)\%20AND\%20classification_c pc: $\left(\mathrm{A} 61^{*}\right) \& \mathrm{l}=\mathrm{en} \& \mathrm{st}=$ true $\& \mathrm{j}=\mathrm{JP}, \mathrm{CN}, \mathrm{US}, \mathrm{DE}$, $\mathrm{EP}, \mathrm{WO}, \mathrm{CA}, \mathrm{MX} \&$ preview $=$ true $\& \mathrm{v}=$ analysis $\& \mathrm{p}=0$. [Último acceso: 11 Febrero 2020].

[2] C. M. P. Moure, «Articular Prosthesis Of The Patella And Distal Femur». Mexico Patente 083-687-799-295-721, 16032005.

[3] C. A. R. García, E. C. Paredes, J. N. C. Castillo, J. A. Rosales y J. E. H. D. León, «Automatic Knee Prosthesis.». Mexico Patente 181-838-813-515-953, 06102017. 
[4] N. Conlisk, P. Pankaj y C. R. Howie, «Stress Shielding in the Distal Femur after Total Knee Arthroplasty.,» de ORS 2011 Annual Meeting, Edinburgh, UK, 2011.

[5] M. Sanjay, S. K. Gupta, A. C. Amar, R. J y S. Chitranjan, «Review Article: Osteolysis After Total Knee Arthroplasty.» Elsevier, vol. 22, nº 6, 2007.

[6] J. L. M. Rodríguez y C. A. C. Méndez, «Diseño de prótesis interna de rodilla.,» de VII Conferencia Científica Internacional de Ingeniería Mecánica. COMEC-2012, La Habana, Cuba, 2012.

[7] P. Loeza-Magaña, «Rehabilitación en artroplastia de rodilla: modelo de 3 fases,» Revista Colombiana de Medicina Física y Rehabilitación, vol. 25, 2015.

[8] M. J. Pappas, G. Makris y F. Buechel, «Contact stresses in metal-plastic total knee replacements.,» Biomed Eng Tech Rep, vol. $1, \mathrm{n}^{\mathrm{o}} 7,1987$.

[9] J. B. Finlay, R. B. Bourne, W. J. Kraemer, T. K. Moroz y C. H. Rorabeck, «Stiffness of bone underlying the tibial plateaus of osteoarthritic and normal knees.,» Clinical orthopaedics and related research, vol. 247, 1989.

[10] U. Witzel, «Biomechanische und tribologische Aspekte der Kniegelenkendoprothetik.» de In Praxis der Knieendoprothetik., Berlin, Heidelberg, Springer, 2001.

[11] D. Reilly, P. S. Walker, M. Ben-Dov y F. C. Ewald, «Effects of tibial components on load transfer in the upper tibia,» Clinical orthopaedics and related research, vol. 165, 1982.
[12] I. Hvid, «Trabecular bone strength at the knee.»Clinical orthopaedics and related research, vol. 227, 1988.

[13] K. Murase, R. D. Crowninshield, D. R. Pedersen y T. S. Chang, «An analysis of tibial component design in total knee arthroplasty.,» Journal of biomechanics, vol. 16, 1983.

[14] R. B. Bourne y J. B. Finlay, «The influence of tibial component intramedullary stems and implant-cortex contact on the strain distribution of the proximal tibia following total knee arthroplasty. An in vitro study.» Clinical orthopaedics and related research, vol. 208, 1986.

[15] C. L. Peters, J. Erickson, R. G. Kloepper y R. A. Mohr, «Revision total knee arthroplasty with modular components inserted with metaphyseal cement and stems without cement,» The Journal of arthroplasty, vol. 20, 2005.

[16] H. Attara, S. Ehtemam-Haghighia, N. Soroa, D. Kenta y M. S. Dargusch, «Additive manufacturing of low-cost porous titaniumbasedcomposites for biomedical applications: Advantages, challenges andopinion for future development,» Journal of Alloys and Compounds, vol. 827, 2020.

[17] C.-C. Huanga, Ming-JunLia, P.-I. Tsaib, P.-C. Kunga, S.-Y. Chena, J.-S. Sunc y Nien-TiTsoua, «Novel design of additive manufactured hollow porous implants,» Dent. Mater. , 2020.

[18] L. A. Lehmann, R. E. Alvarez, A. Macovski, W. R. Brody, N. J. Pelc, S. J. Riederer y A. L. \& Hall, «Generalized image combinations in dual KVP digital radiography.,» vol. $8, \mathrm{n}^{\circ} 5,1981$. 
[19] J. T. Bushberg, The essential physics of medical imaging, Lippincott Williams \& Wilkins, 2002.

[20] K. T. Saxena R, «Computer modeling for evaluating trabecular bone biomechanics» de Mechanical testing of bone and the boneimplant interface, Boca Raton, USA, CRC Press, 2000, pp. 407 - 36.

[21] G. Bevill, S. K. Eswaran, A. Gupta, P. Papadopoulos y T. M. Keaveny, «Influence of bone volume fraction and architecture on computed large-deformation failure mechanisms in human trabecular bone,» Bone, pp. 1218 - 25, 2006.

[22] V. Luzzati, A. Tardieu, T. GulikKrzywicki, E. Rivas y F. Reiss-Husson, «Structure of the cubic phases of lipid-water systems.,» Nature, vol. 220, 1968.

[23] Z. Yosibash, N. Trabelsi y C. Milgrom, «Reliable simulations of the human proximal femur by high-order finite element analysis validated by experimental observations.,» Journal of biomechanics Vol. 40., 2007.

[24] F. C. Buroni, P. E. Commisso, A. P. Cisilino y M. Sammartino, «Determinación de las constantes elásticas anisótropas del tejido óseo utilizando tomografías computadas. Aplicación a la construcción de modelos de elementos finitos,» vol. 18, 2004.

[25] D. Wirtz, N. Schiffers, T. Pandorf, K. Radermacher, D. Weichert y R. Forst, «Critical evaluation of known bone material properties to realize anisotropic $\mathrm{FE}$ simulation of the proximal femur,» vol. 33, 2000.

[26] A. Cisilino, D. D’Amico, F. Buroni, P. Commisso, M. Sammartino y C. Capiel, «Construcción de modelos computacionales para el análisis de esfuerzos mecánicos de piezas óseas utilizando imágenes de TC: aplicación a la articulación gleno-humeral.,» Revista argentina de radiología, vol. $72, n^{\circ} 4$, 2008.

[27] H. S. Park, Y. J. Lee, S. H. Jeong y T. G. Kwon, «Density of the alveolar and basal bones of the maxilla and the mandible,» vol. $133,2008$.

[28] M. Quilez, B. A. Seral y M. Peréz, «Biomechanical evaluation of tibial bone adaptation after revision total knee arthroplasty: A comparison of different implant systems,» PLoS ONE 12(9), 2017.

[29] M. M. Hernández, M. M. Fernández y J. R. Ramírez, «Variaciones de la densidad y de la concentración mineral ósea entre distintas comunidades,» Anales de Pediatría, vol. 52, nº 4, pp. 319 - 326, 2000.

[30] S. Cowin y M. M. Mehrabadi, "Identification of the elastic symmetry of bone,» Journal of Biomechanics, vol. 22, 1989.

[31] D. Reilly y A. H. Burstein, «The mechanical properties of cortical bone,» Journal of Bone and Joint Surgery, vol. 56, 1974.

[32] R. Ashman, «A continous wave technique for the measurement of the elastic properties of cortical bone.,» Journal of Biomechanics, vol. 17, 188.

[33] D. T. Reilly y A. H. Burstein, «The mechanical properties of cortical bone,» Journal of Bone and Joint Surgery, vol. 156A, 1974.

[34] F. M. Elise, U. U. Ginu y I. Amira, «Bone Mechanical Properties in Healthy and Diseased States.» Annu Rev Biomed Eng, 
J. A. Mina, C. A. Poblano, O. Barceinas, J. Henao, J. Corona

Revista Colombiana de Materiales, ISSN 2256-1013, No 17, pp. 53-71, 2021. http://doi.org/10.17533/udea.rcm.n17a06

vol. 20, 2018. 